\title{
Fabrication and Characterization of High-Bonding-Strength Al/Ti/ Al-Laminated Composites via Cryorolling
}

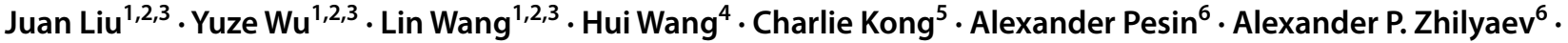 \\ Hailiang $\mathrm{Yu}^{1,2,3}$
}

Received: 3 November 2019 / Revised: 8 January 2020 / Published online: 14 April 2020

(c) The Chinese Society for Metals (CSM) and Springer-Verlag GmbH Germany, part of Springer Nature 2020

\begin{abstract}
Sandwich-like Al/Ti/Al-laminated composites have many advantages such as low density and high specific strength with value in mechanical manufacturing and aerospace engineering. Here, $\mathrm{Al} / \mathrm{Ti} / \mathrm{Al}$-laminated composites were fabricated by hot roll bonding and subsequent processes: cryorolling $\left(-190^{\circ} \mathrm{C}\right.$ and $\left.-100{ }^{\circ} \mathrm{C}\right)$, cold rolling $\left(25^{\circ} \mathrm{C}\right)$, and hot rolling $\left(300^{\circ} \mathrm{C}\right)$. Their bonding strength and mechanical properties were then studied by an Autograph AGS-X universal electronic testing machine. The results show that cryorolling can improve the interface bonding strength and tensile strength of Al/Ti/Allaminated composites. For the Al/Ti/Al-laminated composites subjected to cryorolling at $-100{ }^{\circ} \mathrm{C}$, they have the highest strength near $260 \mathrm{MPa}$ - this is $48 \mathrm{MPa}$ and $41 \mathrm{MPa}$ higher than the laminated composites subjected to cold and hot rolling, respectively. These results also show the strongest peeling strength. Finally, the mechanisms of the enhancement of bonding strength and mechanical properties of Al/Ti/Al-laminated composites subjected to cryorolling were mainly discussed.
\end{abstract}

Keywords Laminated composites $\cdot$ Cryorolling $\cdot$ Bonding strength $\cdot$ Peeling strength $\cdot$ Mechanical property $\cdot$ Bonding mechanism

Available online at http://link.springer.com/journal/40195.

Hailiang Yu

yuhailiang1980@tom.com; yuhailiang@csu.edu.cn

1 State Key Laboratory of High Performance Complex Manufacturing, Central South University, Changsha 410083, China

2 College of Mechanical and Electrical Engineering, Central South University, Changsha 410083, China

3 Light Alloys Research Institute, Central South University, Changsha 410083, China

4 Research Center for Advanced Science and Technology, The University of Tokyo, Meguro, Tokyo 1530041, Japan

5 Mark Wainwright Analytical Centre, University of New South Wales, Sydney, NSW 2052, Australia

6 Laboratory of Mechanics of Gradient Nanomaterials, Nosov Magnitogorsk State Technical University, Magnitogorsk, Russia 455000

\section{Introduction}

Modern technology requires materials with high strength and good ductility. However, strengthening can often decrease ductility. Fortunately, layered and shell-core structures can improve the strength without the ductility drop [1-3]. Laminated composites (LCs) fabricated by two or more materials may have superior properties of each component [4], and such composites are widely used in petroleum, chemical, automobile, and aerospace engineering. Theories such as recrystallization theory, metallic bond theory, and diffusion theory have promoted the manufacturing technologies for development of LC plates, including explosive cladding [5, 6], hot pressing $[7,8]$, ultrasonic consolidation $[9,10]$, and roll bonding [11-15]. For LC production, people focus on the microstructure, mechanical properties, fracture mechanism, and interface properties [16-24]. In addition, surface treatment methods [21], microelement distribution [22, 24], and thickness ratio between soft and hard layers $[25,26]$ may also affect the mechanical properties of LCs.

As an ultra-low-temperature deformation technique, cryorolling inhibits the dynamic recovery process and produces nanocrystalline materials with a smaller deformation 
versus high-temperature deformation techniques [27-31]. Wang et al. [27] obtained AA1060 sheets with a strength up to $180 \mathrm{MPa}$ by cryorolling, which is about 2.5 times higher than that before rolling. Yu et al. [28] reported that $\mathrm{Cu}$ sheets fabricated by asymmetrical cryorolling had finer grains, higher strength, and better thermal stability. Bhattacharjee et al. [31] reported that cryorolling resulted in better mechanical properties of an $\mathrm{AlCoCrFeNi} 2.1$ alloy versus a control sample subjected to cold rolling.

Recently, cryorolling has also been used to develop LCs with good mechanical properties. Takagawa et al. [32] adopted cryogenic accumulative roll bonding to obtain nanostructured $\mathrm{Cu}-2.0 \mathrm{Ni}-0.5 \mathrm{Si}-0.1 \mathrm{Zr}$ alloy with improved tensile properties without reduced electrical conductivity. $\mathrm{Yu}$ et al. [33] reported that cryorolling can further improve the ultrafine-grained AA1060 sheets subjected to accumulative roll bonding. It was worth noting that the cryogenic temperature was $-196{ }^{\circ} \mathrm{C}$ in these studies [27-33], and there are no reports on the effects of intermediate temperatures between $-196^{\circ} \mathrm{C}$ and room temperature on the bonding strength and mechanical properties of LCs during cryorolling.

$\mathrm{Al} / \mathrm{Ti} / \mathrm{Al} \mathrm{LCs}$ combine the advantages of $\mathrm{Al}$ and $\mathrm{Ti}$ such as low density, high specific strength, and good corrosion resistance. They have great application prospects in mechanical manufacturing and aerospace engineering [33-36]. There are many studies on the fabrication of $\mathrm{Al} / \mathrm{Ti} / \mathrm{Al} \mathrm{LCs}$ by hot roll bonding [37-43]. During hot roll bonding, Ti and $\mathrm{Al}$ atoms form a multilayer Ti/Al diffusion system [37], and $\mathrm{TiAl}_{3}$ forms in the interface between $\mathrm{Ti}$ and $\mathrm{Al}$ layers [40]. The grain size of the $\mathrm{TiAl}_{3}$ in the $\mathrm{Ti} / \mathrm{TiAl}_{3}$ interface was much finer than that in the $\mathrm{Al} / \mathrm{TiAl}_{3}$ interface [38], and the diffusion rate of $\mathrm{Al}$ in $\mathrm{TiAl}_{3}$ was faster than that of $\mathrm{Ti}$ [39]. The peeling strength and mechanical properties of the Ti/ Al LCs are significantly affected by the width of the intermetallic layer. Recently, Karfoul and Tatlock [44] found the possibility of seamless bonding of Ti/Al composite plates under non-vacuum conditions. To date, there have been few reports on the bonding strength and mechanical properties of $\mathrm{Al} / \mathrm{Ti} / \mathrm{Al} \mathrm{LCs}$ subjected to cryorolling.

In this study, $\mathrm{Al} / \mathrm{Ti} / \mathrm{Al} \mathrm{LCs}$ were fabricated by hot roll bonding combined with cryorolling $\left(-190{ }^{\circ} \mathrm{C}\right.$ and $-100{ }^{\circ} \mathrm{C}$, respectively), cold rolling, or hot rolling. Their mechanical properties and bonding strength were studied and discussed.
The results show that the cryorolling at $-100{ }^{\circ} \mathrm{C}$ results in excellent bonding strength and mechanical properties of $\mathrm{Al} /$ Ti/Al LCs.

\section{Materials and Methods}

The sheets adopted here were commercially pure $\mathrm{Ti}$ (TA2) and commercially pure $\mathrm{Al}$ (AA1100) sheets. Their chemical compositions are listed in Tables 1 and 2, respectively. The thicknesses of the $\mathrm{Ti}$ and $\mathrm{Al}$ sheets were $0.2 \mathrm{~mm}$ and $0.4 \mathrm{~mm}$, respectively. The Ti sheets were vacuum-annealed at $550{ }^{\circ} \mathrm{C}$ for $30 \mathrm{~min}$, and the $\mathrm{Al}$ sheets were vacuum-annealed at $400{ }^{\circ} \mathrm{C}$ for $1 \mathrm{~h}$ before rolling. Annealing was performed in a SA2-6-12TP resistance heating furnace. After annealing, both $\mathrm{Ti}$ and $\mathrm{Al}$ sheets were surface-treated to remove the oxide film. The Ti and $\mathrm{Al}$ sheets were then stacked with a sandwich-like structure as Al/Ti/Al LCs. The sandwichlike $\mathrm{Al} / \mathrm{Ti} / \mathrm{Al} \mathrm{LCs}$ were heat-treated at $300^{\circ} \mathrm{C}$ for $10 \mathrm{~min}$ to improve the bonding quality between $\mathrm{Al} / \mathrm{Ti}$ interface and then rolled to a total thickness of $0.5 \mathrm{~mm}$ (rolling reduction ratio 50\%) after two rolling passes. The hot roll-bonded $\mathrm{Al} /$ $\mathrm{Ti} / \mathrm{Al} \mathrm{LCs}$ were then further processed to $0.42 \mathrm{~mm}$ (rolling reduction ratio $16 \%)$, by cryorolling $\left(-190{ }^{\circ} \mathrm{C}\right.$ and $\left.-100{ }^{\circ} \mathrm{C}\right)$, cold rolling $\left(25^{\circ} \mathrm{C}\right)$, or hot rolling $\left(300^{\circ} \mathrm{C}\right)$. The rolling speed was $2 \mathrm{~m} \mathrm{~min}^{-1}$ in a multifunction rolling mill with 80-mm-diameter work rolls.

After rolling, peeling tests and tensile tests were carried out by an Autograph AGS-X universal electronic testing machine to study the bonding strength and mechanical properties of the Al/Ti/Al LCs on an electronic testing machine. The specimens used for the peeling test were $6 \mathrm{~mm}$ in width and $120 \mathrm{~mm}$ in length. During the peeling tests, the crosshead speed was $50 \mathrm{~mm} \mathrm{~min}^{-1}$. The peeling strength was the average peel force divided by the specimen width (Eq. (1)):

$\sigma_{\mathrm{p}}=F / W$.

Here, $\sigma_{\mathrm{p}}\left(\mathrm{N} \mathrm{mm}^{-1}\right)$ is the peeling strength, $F(\mathrm{~N})$ is the average peeling force, and $W(\mathrm{~mm})$ is the width of the peeling specimen. The specimens for tensile testing were $36 \mathrm{~mm}$ long and $5 \mathrm{~mm}$ wide. The peeling tests and tensile tests were repeated three times. During tensile testing, the strain rate
Table 1 Chemical composition (wt $\%$ ) of AA1100 sheets

Table 2 Chemical composition (wt $\%$ ) of TA2 sheets

\begin{tabular}{lllllllll}
\hline $\mathrm{Al}$ & $\mathrm{Fe}$ & $\mathrm{Si}$ & $\mathrm{Cu}$ & $\mathrm{Ni}$ & $\mathrm{Zn}$ & $\mathrm{Mg}$ & $\mathrm{Mn}$ & $\mathrm{Ti}$ \\
\hline $\mathrm{Bal}$ & 0.46 & 0.18 & 0.11 & 0.01 & 0.01 & $<0.01$ & $<0.01$ & 0.005 \\
\hline
\end{tabular}

\begin{tabular}{lllllll}
\hline $\mathrm{Ti}$ & $\mathrm{Fe}$ & $\mathrm{Si}$ & $\mathrm{O}$ & $\mathrm{C}$ & $\mathrm{N}$ & $\mathrm{H}$ \\
\hline $\mathrm{Bal}$ & 0.30 & 0.15 & 0.15 & 0.10 & 0.05 & 0.015 \\
\hline
\end{tabular}


was $1.0 \times 10^{-3} \mathrm{~s}^{-1}$. In addition, a triboindenter was used to test the nanohardness of $\mathrm{Al}$ and $\mathrm{Ti}$ layers with $30 \mathrm{mN}$ testing load.

The fracture surface of the specimens after tensile testing and peeling testing was observed by TESCAN MIRA3 LMU scanning election microscopy (SEM). The interface morphology of Ti/Al was examined via an optical microscope (OM). The elemental distribution near Ti/Al interface was analyzed by energy-dispersive spectrometry (EDS).

\section{Results}

Figure 1 shows the morphology of the $\mathrm{Al} / \mathrm{Ti} / \mathrm{Al} \mathrm{LCs}$ interface after rolling. In this figure, the $\mathrm{Ti} / \mathrm{Al}$ interface is serrated due to $\mathrm{Al}$ squeezing into the Ti layer. Figure 1a, b shows the interface morphology of the Al/Ti/Al LCs by cryorolling. The interface is rough and jagged, and the interface is wide and deep in the Ti layer. The interface becomes smooth and straight as the rolling temperature rises (Fig. 1c). However, the interface becomes wider with the further temperature increases, and the flatness of the interface decreases (Fig. 1d). Ma et al. [45] reported that the interface became rougher when the rolling temperature ranged from 300 to $550{ }^{\circ} \mathrm{C}$.

Figure 2a illustrates the EDS line scan across the Ti/Al interface. Figure 2b-e shows the element distribution of $\mathrm{Al}$ and $\mathrm{Ti}$ atoms near the $\mathrm{Ti} / \mathrm{Al}$ interface for different rolling processes. During rolling, the elemental interdiffusion occurs near the Ti/Al interface forming an intermetallic diffusion layer. The width of the intermetallic diffusion layer increases with rolling temperature. For the Al/Ti/Al LCs subjected to cryorolling, the width of the intermetallic diffusion layer ranges from 2.2 to $2.4 \mu \mathrm{m}$, but it increases to $2.7 \mu \mathrm{m}$ for the $\mathrm{Al} / \mathrm{Ti} / \mathrm{Al} \mathrm{LCs}$ subjected to hot rolling.

Figure 3 a shows the peeling strength curves between the Ti layer and Al layer. The interface bonding strength improves with higher reduction regardless of the rolling temperature. The peeling strength curves gave the average peeling strength of the $\mathrm{Al} / \mathrm{Ti} / \mathrm{Al} \mathrm{LCs}$ with different processing (Table 3). The variation in the average peeling strength with rolling temperature is shown in Fig. 3b. The bonding strength of the Al/Ti/Al LC subjected to cold rolling has the lowest value of $6.4 \mathrm{~N} \mathrm{~mm}^{-1}$. This is slightly lower than the sample subjected to hot rolling. The bonding strength of the Al/Ti/Al LCs sample prepared by cryorolling increases
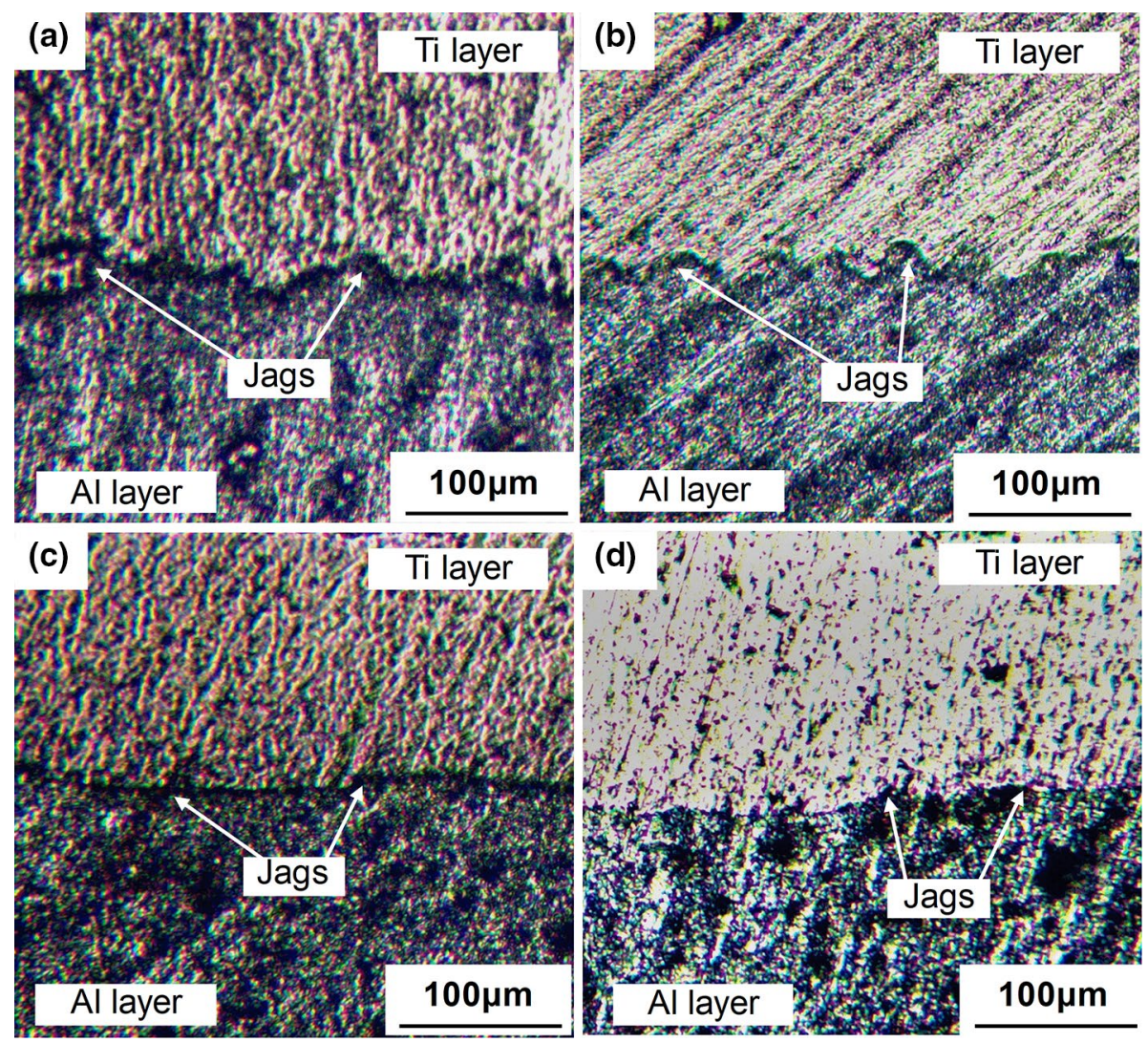

Fig. 1 Morphologies of interface of an Al/Ti/Al-laminated composite subjected to a cryorolling at $-190{ }^{\circ} \mathrm{C}, \mathbf{b}$ cryorolling at $-100{ }^{\circ} \mathrm{C}, \mathbf{c}$ cold rolling, $\mathbf{d}$ hot rolling 
(a)

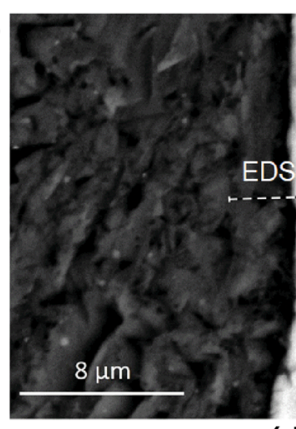

(c)

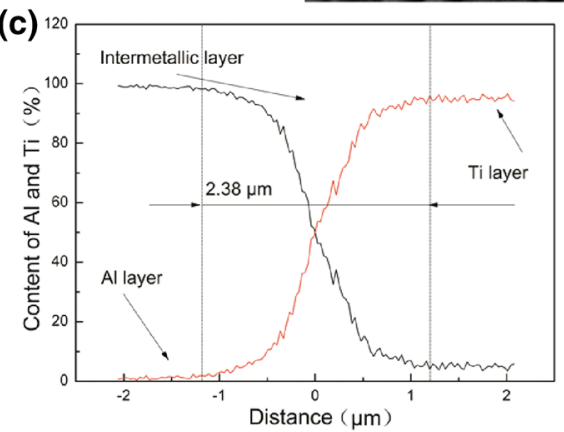

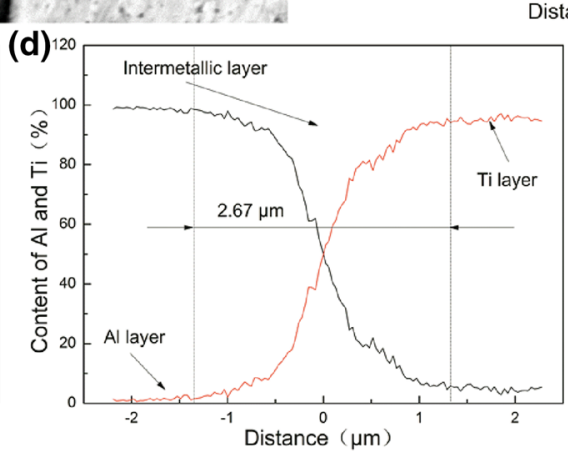
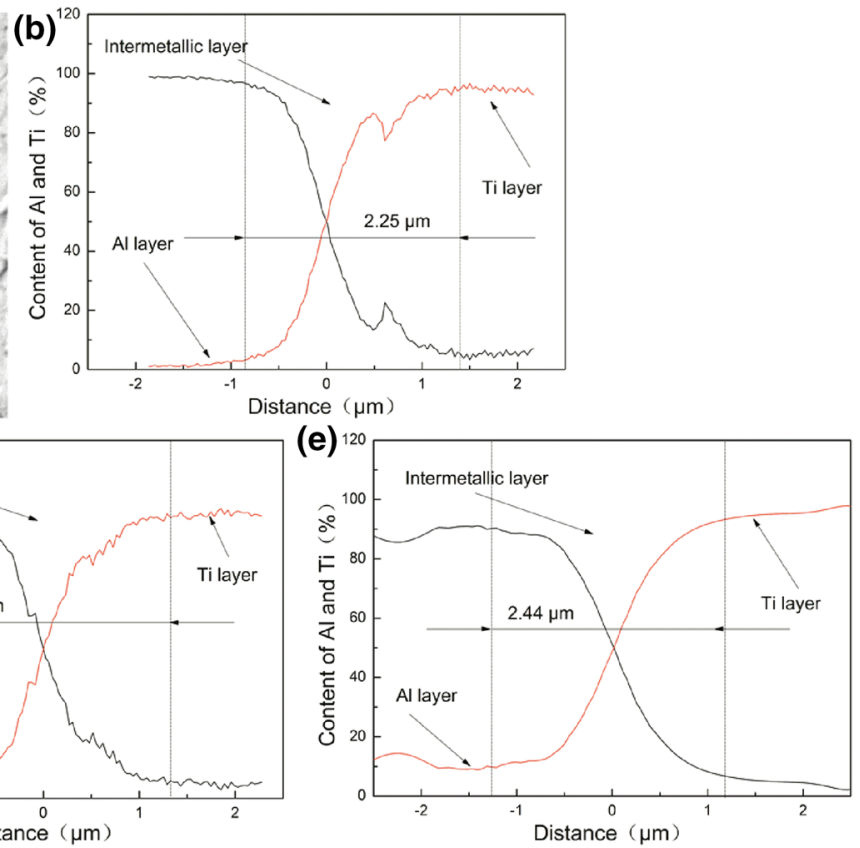

Fig. 2 a Illustration of the EDS analysis of the Al/Ti/Al LCs. Element distribution near the interface in the rolled specimens: $\mathbf{b}$ cryorolling at $-190{ }^{\circ} \mathrm{C}, \mathbf{c}$ cryorolling at $-100{ }^{\circ} \mathrm{C}, \mathbf{d}$ cold rolling, e hot rolling
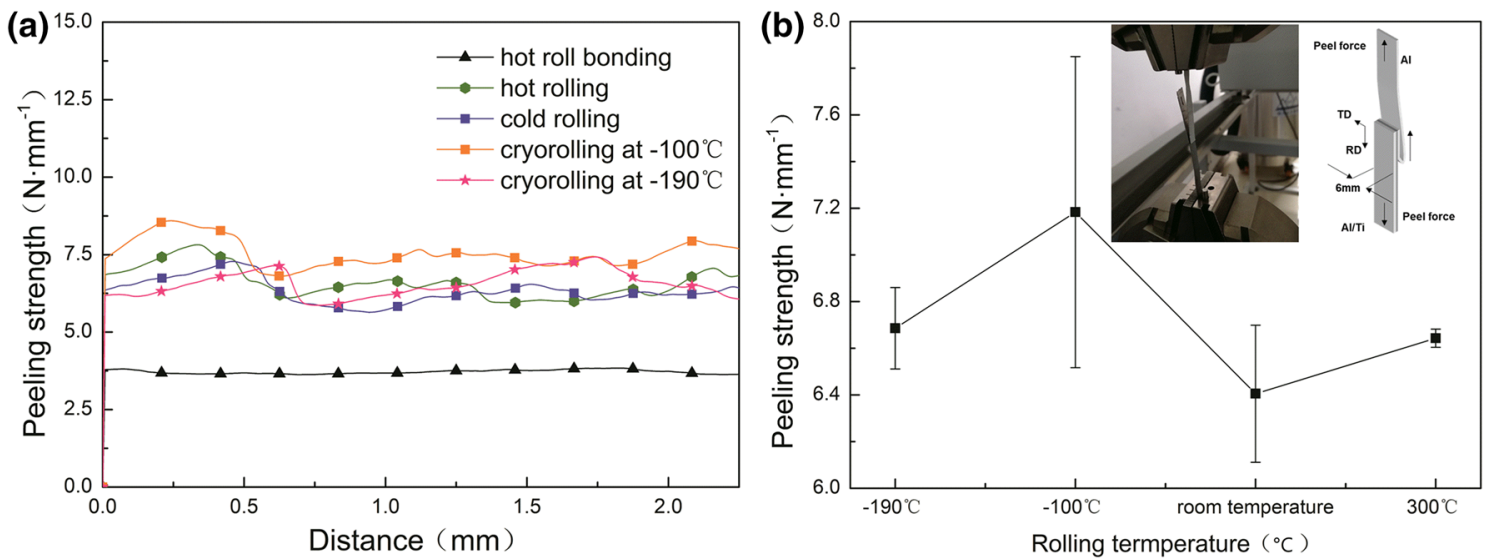

Fig. 3 a Peeling strength-distance curves of $\mathrm{Al} / \mathrm{Ti} / \mathrm{Al} \mathrm{LCs,} \mathbf{b}$ peeling strength versus the rolling temperature of the $\mathrm{Al} / \mathrm{Ti} / \mathrm{Al} \mathrm{LCs} \mathrm{with} \mathrm{the} \mathrm{thick-}$ ness of $0.42 \mathrm{~mm}$. The illustration in $\mathbf{b}$ shows the schematic diagram of the peeling test

Table 3 Peeling strength and mechanical tensile properties of $\mathrm{Al} / \mathrm{Ti} / \mathrm{Al} \mathrm{LCs}$ with the thickness of $0.42 \mathrm{~mm}$

\begin{tabular}{lllrlr}
\hline $\begin{array}{l}\text { Rolling tempera- } \\
\text { ture }\left({ }^{\circ} \mathrm{C}\right)\end{array}$ & $\sigma_{\mathrm{p}}\left(\mathrm{N} \mathrm{mm}^{-1}\right)$ & $\sigma_{\mathrm{b}}(\mathrm{MPa})$ & $\delta_{\mathrm{s}}(\%)$ & \multicolumn{2}{l}{ Nanohardness $(\mathrm{GPa})$} \\
\cline { 4 - 6 } & & & & Ti layer & Al layer \\
\hline-190 & $6.7 \pm 0.2$ & $234.8 \pm 8.5$ & $10.4 \pm 0.1$ & $2.8 \pm 0.1$ & $0.50 \pm 0.04$ \\
-100 & $7.2 \pm 0.7$ & $261.4 \pm 1.6$ & $12.4 \pm 0.4$ & $2.9 \pm 0.1$ & $0.55 \pm 0.01$ \\
25 & $6.4 \pm 0.3$ & $215.2 \pm 2.9$ & $9.4 \pm 1.1$ & $2.7 \pm .02$ & $0.48 \pm 0.02$ \\
300 & $6.6 \pm 0.1$ & $219.4 \pm 0.3$ & $13.2 \pm 0.2$ & $2.6 \pm 0.1$ & $0.43 \pm 0.03$ \\
\hline
\end{tabular}


versus the samples subjected to cold rolling. The bonding strength is highest in the $-100{ }^{\circ} \mathrm{C}$ samples-this strength is $7.2 \mathrm{~N} \mathrm{~mm}^{-1}$ and is $12.5 \%$ higher than the sample subjected to cold rolling.

Figure 4 shows the SEM morphology of the $\mathrm{Ti}$ and $\mathrm{Al}$ surface after peeling tests for the specimens prepared after hot roll bonding. There are many cracks on the surface of the Ti side perpendicular to the rolling direction. In addition, there are few residual Al chips on the Ti surface: These are characterized by the bonding mode studied via mechanical locking, and the results are similar to Hwang et al. [46].

The morphologies of the Ti surfaces and Al surfaces after further rolling processing are shown in Fig. 5. The cracks on the Ti surface are wider than those on hot roll bonded. The residual Al chips increase like a "ridge"- the ridge width is much wider for the specimen subjected to cryorolling. The formation of this "Al ridge" is because the bonding strength between the $\mathrm{Ti}$ and $\mathrm{Al}$ layers is higher than the tensile strength of the $\mathrm{Al}$ layer. The $\mathrm{Al}$ is necked and fractured, and the "Al ridge" forms during peeling [47]. The width of the cracks on the Ti surface first decreases and reaches the minimum value at $25^{\circ} \mathrm{C}$ as rolling temperature increases (Fig. 5a, c, e, g). It then widens with increasing rolling temperature. The area fraction of the bond-well area between $\mathrm{Ti}$ and $\mathrm{Al}$ after peeling tests is shown in Fig. 6.

The tensile curves and mechanical properties of the Al/ Ti/Al LCs are shown in Fig. 7 and Table 3, respectively. The results indicate that both cryorolling and hot rolling can improve the tensile strength and ductility of the Al/Ti/ Al LCs versus samples subjected to cold rolling. In addition, the $\mathrm{Al} / \mathrm{Ti} / \mathrm{Al} \mathrm{LCs}$ subjected to cryorolling at $-100{ }^{\circ} \mathrm{C}$ have the best properties with a tensile strength of $260 \mathrm{MPa}$, and the failure strain is $12.4 \%$.

Figure 8 shows the SEM morphology of the tensile fracture surface. The interface delamination of the $\mathrm{Al} / \mathrm{Ti} / \mathrm{Al}$ LCs can be seen in the tensile fracture. The Al/Ti/Al LCs subjected to cryorolling at $-100{ }^{\circ} \mathrm{C}$ have obvious dimples in both $\mathrm{Al}$ and $\mathrm{Ti}$ layers, and the dimples in the Ti layer are nearly the same size. The hot-rolled Al/Ti/Al LCs have dimples that appear in the Ti layer and the $\mathrm{Al}$ layer, and the $\mathrm{Al}$ has a ridge-like fracture due to the strong necking. Both the $\mathrm{Al} / \mathrm{Ti} / \mathrm{Al} \mathrm{LCs}$ subjected to cryorolling at $-100{ }^{\circ} \mathrm{C}$ and hot rolling show a plastic fracture with good ductility. However, the $\mathrm{Al} / \mathrm{Ti} / \mathrm{Al} \mathrm{LCs}$ subjected to cryorolling at $-190{ }^{\circ} \mathrm{C}$ or cold rolling has very few dimples on the $\mathrm{Al}$ layers and only a few shallow dimples on the Ti layer. There are also a few flat areas on the fracture surface, and thus, the ductility of the $\mathrm{Al} / \mathrm{Ti} / \mathrm{Al}$ LCs decreases.

The nanohardness values of the Ti layer and $\mathrm{Al}$ layer of $\mathrm{Al} / \mathrm{Ti} / \mathrm{Al} \mathrm{LCs}$ are listed in Table 3. The change in the nanohardness of the $\mathrm{Al}$ layer and the Ti layer with temperature is shown in Fig. 9. The nanohardness value of the Ti layer by cryorolling is lower than $3.25 \mathrm{GPa}$ reported by Fomenkothis is likely because their test load was much smaller than $30 \mathrm{~N}$ [48]. In Fig. 9, the Al layer and Ti layer have the maximum nanohardness values for the Al/Ti/Al LCs subjected to cryorolling at $-100{ }^{\circ} \mathrm{C}$, and the nanohardness decreases with increasing rolling temperature.

\section{Discussion}

\subsection{Bonding Mechanism and Bonding Strength}

Severe shear deformation occurs on the surface of $\mathrm{Ti}$ and $\mathrm{Al}$ layers during $\mathrm{Al} / \mathrm{Ti} / \mathrm{Al} \mathrm{LCs}$ rolling due to the different deformation capacity of $\mathrm{Ti}$ and $\mathrm{Al}$ layers and the difference in friction between the contact surfaces. The cracks first appear on the surface of Ti layer due to its poor deformation ability (Fig. 4). The Al will be squeezed into those cracks under the action of the rolling force, which leads to mechanical locking [49]. Generally, the LC bonding mode in the early rolling stage is mechanical locking [46]. Here, the deformation capacity of the Ti layer might decrease with decreasing rolling temperature, the number of cracks increases, and the crack size becomes wider (Fig. 5a, c, e, g). More Al squeeze into the cracks, which leads to wider cracks, and the mechanical bonding strength is then improved with
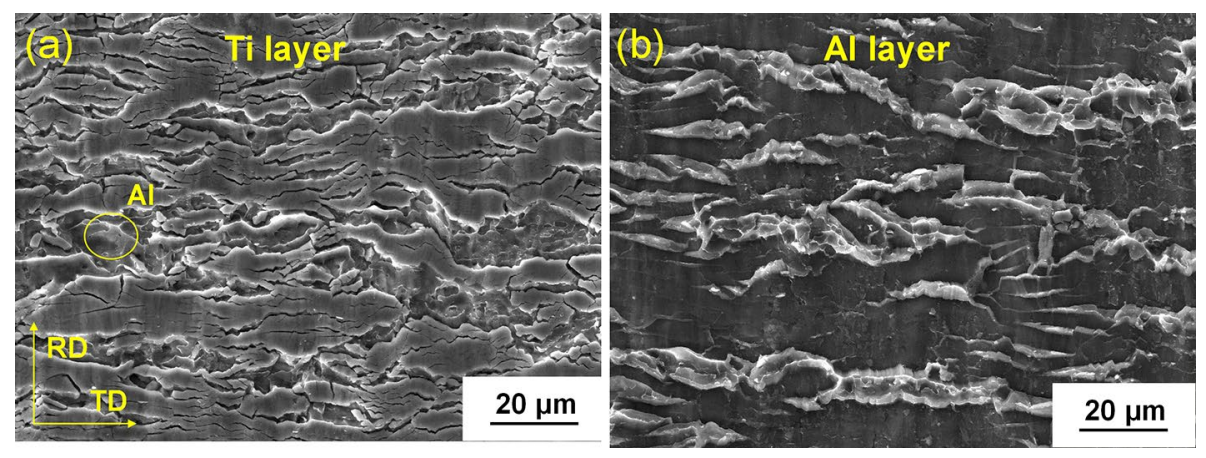

Fig. 4 SEM images of surfaces after peeling test for hot roll-bonded specimen: a Ti layer; $\mathbf{b}$ Al layer 

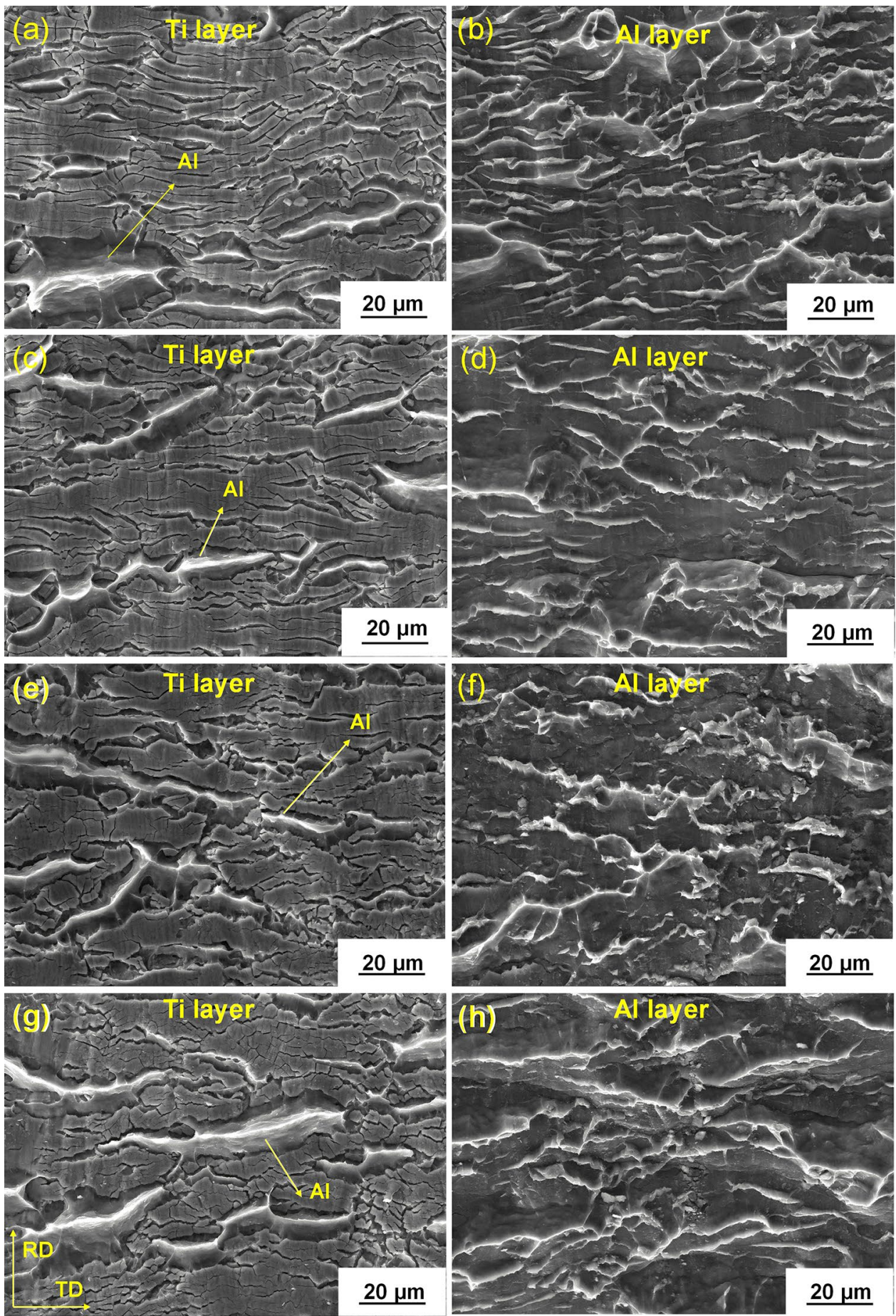

Fig. 5 SEM images of Ti surface and $\mathrm{Al}$ surface after peeling tests for the specimens subjected to cryorolling at $\mathbf{a}, \mathbf{b}-190{ }^{\circ} \mathrm{C}$ and $\mathbf{c}, \mathbf{d}-100{ }^{\circ} \mathrm{C}$, $\mathbf{e}, \mathbf{f}$ cold rolling, $\mathbf{g}, \mathbf{h}$ hot rolling

increasing contact area between the two metals [50]. In addition, cryorolling results in grain refinement [51], which can improve the strength of the materials (Fig. 6). The peeling strength is dependent on the strength of Al layer, when the bonding strength is greater than the tensile strength of the $\mathrm{Al}$ layer. Thus, the higher tensile strength of the $\mathrm{Al}$ layer can increase the bearing capacity of the transverse load at the interface and improves the peeling strength due to improved mechanical locking strength.

In addition, with the formation of the Ti/Al interface, the $\mathrm{Ti}$ and $\mathrm{Al}$ layers form a solid diffusion system during rolling. Under the action of different atomic concentration, the 


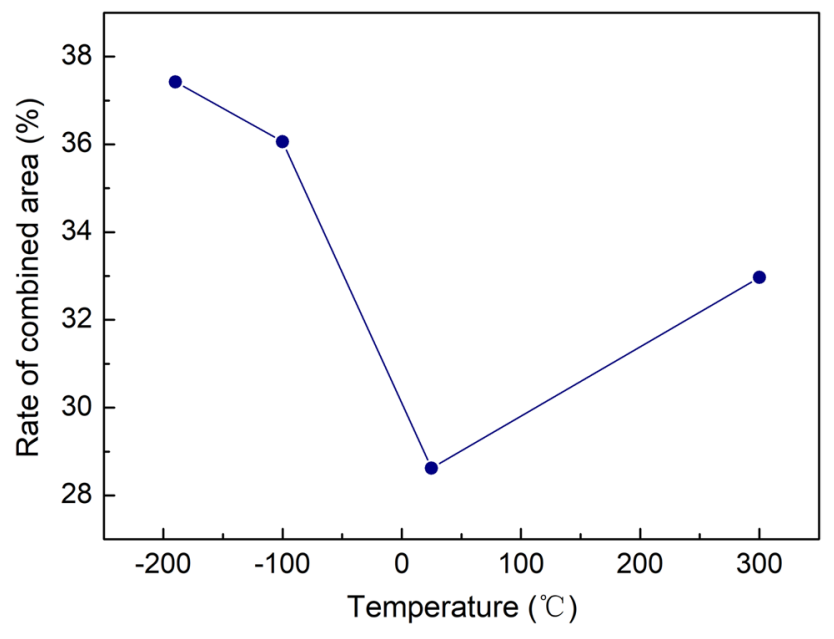

Fig. 6 Area fraction of the combined area between $\mathrm{Ti}$ and $\mathrm{Al}$ after peeling tests

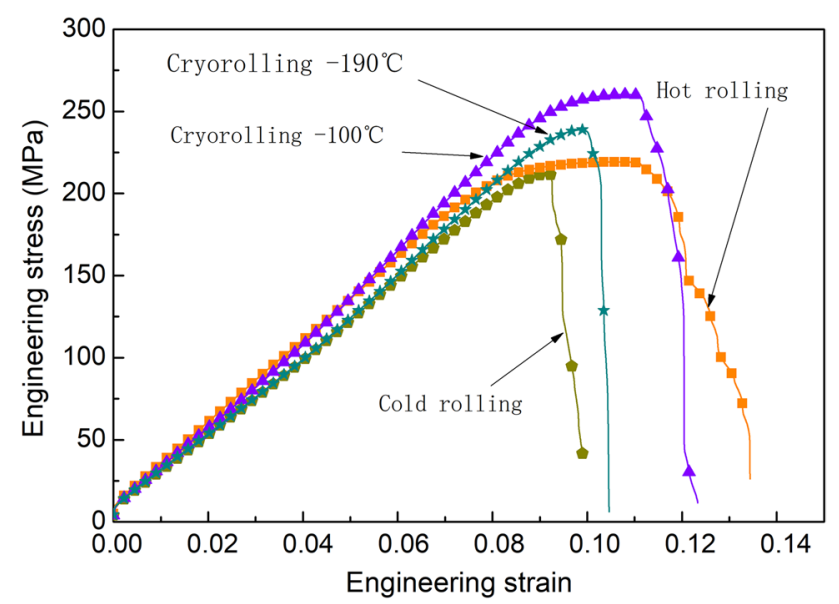

Fig. 7 Engineering stress-stain curves of $\mathrm{Al} / \mathrm{Ti} / \mathrm{Al} \mathrm{LCs}$ subjected to different rolling processes

active $\mathrm{Ti}(\mathrm{Al})$ atoms in $\mathrm{Ti}(\mathrm{Al})$ layer diffuse into the $\mathrm{Al}(\mathrm{Ti})$ layer leading to an intermetallic diffusion layer. The rearrangement of the atoms near the interface results in solution strengthening, and the interface bonding mode changes to metallurgical bonding. Over a certain range, the interfacial bonding strength increases as the intermetallic diffusion layer widens. The width of the interfacial diffusion layer is related to the atomic diffusion rate during rolling. The diffusion modes of the $\mathrm{Ti}$ and $\mathrm{Al}$ during rolling included atomic displacement, pipe diffusion along dislocations, and plastic deformation-induced vacancies. The energy inside an atom determines whether it can be diffused or not, and the diffusion rate is related to the number of atoms in the activated state. The diffusion rate of atoms in the diffusion system can be characterized by the diffusion coefficient [51] as shown in Eq. (2):
$D=D_{0} \exp \left(-\Delta E_{\mathrm{a}} / R T\right)$.

Here, $D$ is the diffusion coefficient, $D_{0}$ is the diffusion constant, $\Delta E_{\mathrm{a}}$ is the diffusion activation energy $\left(\mathrm{J} \mathrm{mol}^{-1}\right)$, $R$ is the gas constant with a value of $8.31 \mathrm{~J} \mathrm{~mol}^{-1} \mathrm{k}^{-1}$, and $T$ is the absolute temperature (K). Temperature is the main factor affecting the diffusion coefficient. A higher temperature leads to more energetic atoms, higher frequency of their vibrations, and a greater chance that the energy of the atoms will exceed the barrier. Therefore, the atomic diffusion rate and the width of the diffusion layer at the Ti/Al interface will significantly increase as the temperature increases. The width of the interfacial diffusion layer increases with higher rolling temperature (Fig. 2). However, the high temperature may result in Kirkendall voids near the Al/Ti interface, which also affect the bonding strength [52]. Thus, the high metallurgical bonding quality will directly affect the peeling strength.

In conclusion, both mechanical locking and metallurgical bonding determine the bonding strength $\left(\sigma_{\mathrm{B}}\right)$, as expressed in Eq. (3):

$\sigma_{\mathrm{B}}=\alpha \sigma_{\mathrm{C}}+\beta \sigma_{\mathrm{M}}$.

Here, the contribution of mechanical locking strength $\left(\sigma_{\mathrm{C}}\right)$ and metallurgical bonding strength $\left(\sigma_{\mathrm{M}}\right)$ is controlled, respectively, by $\alpha$ and $\beta$ parameter. On the other hand, $\sigma_{\mathrm{C}}$ is related to the combined area, and $\sigma_{\mathrm{M}}$ is related to the width of the interfacial diffusion layer. According to the results in Figs. 2, 3, and 6, it can be known that the mechanical locking plays a key role in the enhancement of bonding strength. And the highest bonding strength was earned by cryorolling (Fig. 3).

\subsection{Mechanical Properties}

In Fig. 6, the tensile curves of $\mathrm{Al} / \mathrm{Ti} / \mathrm{Al} \mathrm{LCs}$ vary in stages, which are similar to the shape of $\mathrm{Ti} / \mathrm{Al} / \mathrm{Mg} / \mathrm{Al} / \mathrm{Ti}$ LCs prepared by Mi et al. [53]. The tensile curves show that the tensile progress of the Al/Ti/Al LCs can be divided into three stages. First, the Ti and Al undergo elastic-plastic deformation, and the stress is maximized. Strain localization and the strain redistribution appear in the specimens due to the change of deformation coordination between $\mathrm{Al}$ and $\mathrm{Ti}$. Here, $\mathrm{Ti}$ is the main bearing layer, and the existence of the interface on both sides of Ti restricts the deformation behavior of Ti and transfers the strain to the Al layer-this strain transfer improves the bearing capacity of Ti [2]. Sun et al. [54] described how the LCs have good mechanical properties due to the stress redistribution and the crack front bridging. The constraining effect of the interface changes the deformation behavior of the $\mathrm{Ti}$ so that the higher bonding strength can enhance the tensile strength of the LCs [45]. 

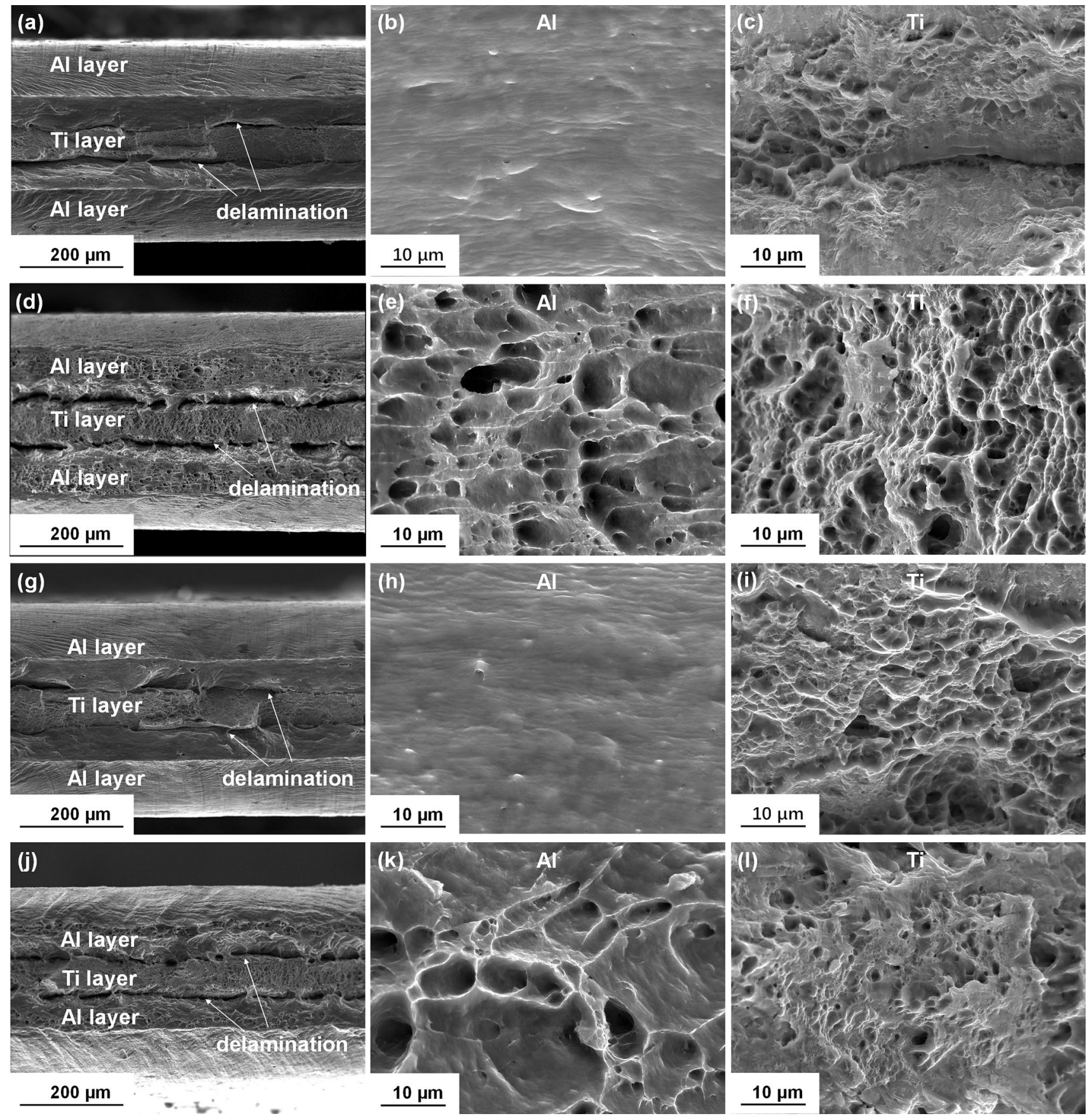

Fig. 8 SEM images of fracture surfaces of $\mathrm{Al} / \mathrm{Ti} / \mathrm{Al}$ LCs subjected to cryorolling at $-190{ }^{\circ} \mathrm{C} \mathbf{a}-\mathbf{c}$ and $-100{ }^{\circ} \mathrm{C} \mathbf{d}-\mathbf{f}$, cold rolling $\mathbf{g}-\mathbf{i}$, hot rolling j-l

The second step is a drop in stress, crack initiation and propagation, and interface delamination. When the local stress at the interface exceeds the bonding strength, microcracks will be generated at the weak interface $[55,56]$. There will be more cracks as the deformation continues. However, the constraining effect prevents lateral extension of cracks. These can only expand along the interface and will eventually delaminate (Fig. 8a, d, g, j). Furthermore, the constraining effect of the interface disappears due to delamination and the rapid decrease in strain.

Third, the Ti layer and Al layer successively fracture. The disappearance of the interfacial constraining effect forms cracks at the interface, the $\mathrm{Ti}$ and $\mathrm{Al}$ layers can then expand rapidly, and the LCs then fracture. Coarse grains 

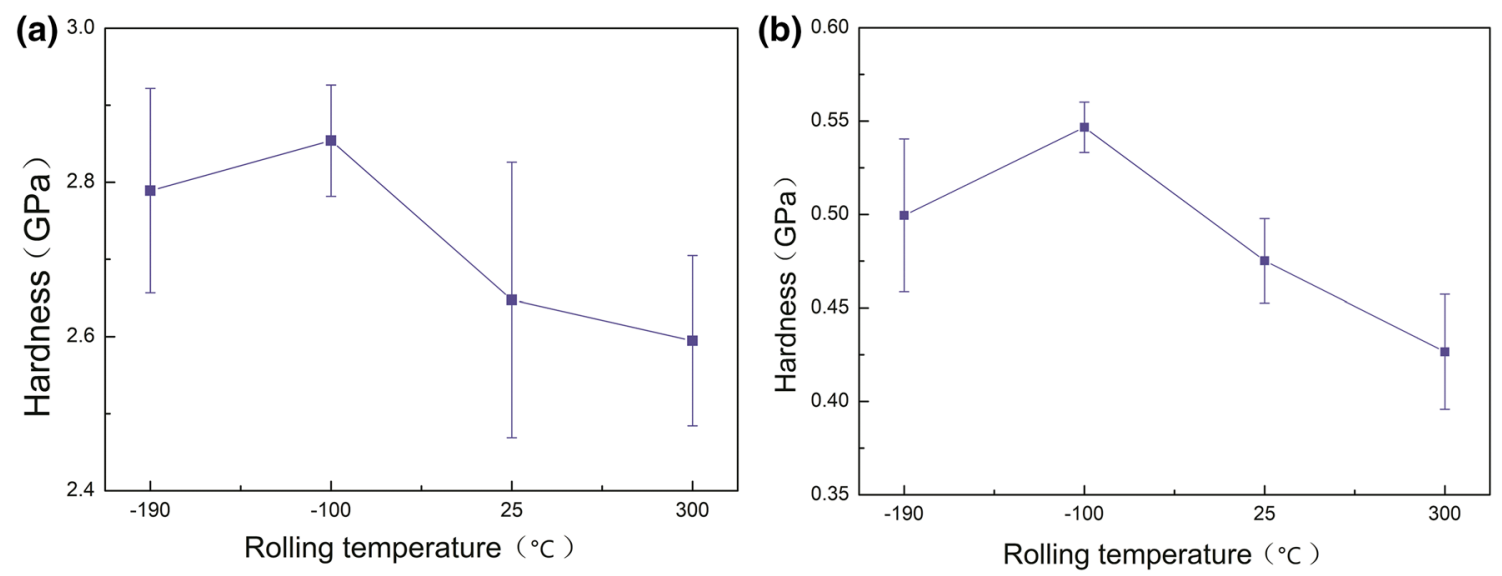

Fig. 9 Nanohardness of a Al layer; $\mathbf{b}$ Ti layer subjected to different rolling processes

can stop the propagation speed of cracks [57], and thus the third stage of the LCs subjected to hot rolling is more obvious than those cryorolled.

In addition to the plastic deformation characteristics and fracture modes, the grain size characteristics of the specimens are another important factor affecting the properties of the composite plates. Cryorolling inhibits the occurrence of the dynamic recovery process-it enhances the dislocation accumulation and grain refinement to improve the strength of the Al layer and the Ti layer [58]. For example, the tensile strength and elongation of commercially pure $\mathrm{Al}$ were improved by cryorolling of Rangaraju et al. [59]. In another example, the grain size of commercial pure $\mathrm{Ti}$ cryorolled at $-196{ }^{\circ} \mathrm{C}$ reached $80 \mathrm{~nm}$ with improved microhardness [60]. In addition, some researchers [27-31] validated the cryorolled metals have finer grains compared to hot-rolled sheets with the same rolling reduction ratio. Figure 9 shows higher microhardness of Ti and $\mathrm{Al}$ prepared by cryorolling. According to the relationship between hardness and yield strength, the strength of singlelayer $\mathrm{Ti}$ or $\mathrm{Al}$ by cryorolling is higher than that subjected to cold rolling and hot rolling. Data on the rule of mixture can be expressed by Eq. (4) [11]:

$\sigma=\sigma_{\mathrm{Ti}} \cdot V_{\mathrm{Ti}}+\sigma_{\mathrm{Al}} \cdot V_{\mathrm{Al}}$.

Here, $\sigma$ is the strength of the composite, $\sigma_{\mathrm{Ti}}$ and $\sigma_{\mathrm{Al}}$ are the strength of the Ti and the $\mathrm{Al}$ layers, and $V_{\mathrm{Ti}}$ and $V_{\mathrm{Al}}$ are the volume ratio of the $\mathrm{Ti}$ and the $\mathrm{Al}$ layers. When the volume ratio of each component remains the same, the hardness of single layer increases, its strength increases, and the strength of composite plate will increase. Thus, cryorolling can improve the strength and ductility of Al/Ti/Al LCs.

\section{Conclusions}

1. Al/Ti/Al LCs were fabricated by cryorolling, cold rolling, or hot rolling. Cryorolling can significantly improve the bonding strength, tensile strength, and ductility of Al/Ti/Al-LCs. Excellent mechanical properties can be obtained with $-100{ }^{\circ} \mathrm{C}$ cryorolling.

2. The bonding strength of the $\mathrm{Al} / \mathrm{Ti} / \mathrm{Al} \mathrm{LCs}$ subjected to cold rolling is lower than that subjected to hot rolling or cryorolling. The bonding strength is highest for the specimens cryorolled at $-100{ }^{\circ} \mathrm{C}$.

3. The bonding strength of $\mathrm{Al} / \mathrm{Ti} / \mathrm{Al} \mathrm{LCs}$ depends on the mechanical locking strength, metallurgical bonding strength, and tensile strength of the $\mathrm{Al}$ layer.

Acknowledgements Yu Hailiang thanks for the financial support by the National Natural Science Foundation of China (Grant Number: 51674303), the National Youth Thousand Plan Program of China, the Huxiang High-Level Talent Gathering Project of HUNAN Province (Grant Number: 2018RS3015), the Innovation Driven Program of Central South University (Grant Number: 2019CX006), and the Research Fund of the Key Laboratory of High Performance Complex Manufacturing at Central South University. Alexander Pesin and Alexander P. Zhilyaev thank the Ministry of Science and Higher Education of Russia Federation for the financial support through the Grant 14.Z50.31.0043. 


\section{References}

[1] Y.J. Wei, Y.Q. Li, L.C. Zhu, Y. Liu, X.Q. Lei, G. Wang, Y.X. Wu, Z.L. Mi, J.B. Liu, H.T. Wang, H.J. Gao, Nat. Commun. 5, 3580 (2014)

[2] M. Huang, C. Xu, G.H. Fan, E. Maawad, W.M. Gan, L. Geng, F.X. Lin, G.Z. Tang, H. Wu, Y. Du, D.Y. Li, K.S. Miao, T.T. Zhang, X.S. Yang, Y.P. Xia, G.J. Cao, H.J. Kang, T.M. Wang, T.Q. Xiao, H.L. Xie, Acta Mater. 153, 235 (2018)

[3] C. Ortiz, M.C. Boyce, Science 319, 1053 (2008)

[4] W. Sun, F. Yang, F.T. Kong, X.P. Wang, Y.Y. Chen, Mater. Charact. 144, 173 (2018)

[5] D.V. Lazurenko, I.A. Bataev, V.I. Mali, A.A. Bataev, I.N. Maliutina, V.S. Lozhkin, M.A. Esikov, A.M. Junior, J. Mater. Des. 102, $122(2016)$

[6] G.H.S.F.L. Carvalho, I. Galvão, R. Mendes, R.M. Leal, A. Loureio, Mater. Manuf. Process. 34, 1243 (2019)

[7] S.B. Ren, H. Xu, J.H. Chen, X.H. Qu, Mater. Manuf. Process. 31, 1377 (2016)

[8] N. Jia, M.W. Zhu, Y.R. Zheng, T. He, X. Zhao, Acta Metall. Sin. (Engl. Lett.) 28, 600 (2015)

[9] J.O. Obielodan, B.E. Stucker, E. Martinez, J.L. Martinez, D.H. Hernandez, D.A. Ramirez, L.E. Muee, J. Mater. Process. Technol. 211, 988 (2011)

[10] J.S. Seo, H.S. Jang, D.S. Park, Mater. Manuf. Process. 30, 1069 (2015)

[11] H.L. Yu, C. Lu, A.K. Tieu, H.J. Li, A. Godbole, C. Kong, Philos. Mag. 98, 1537 (2018)

[12] Y. Du, G.H. Fan, T.B. Yu, N. Hansen, L. Geng, X.X. Huang, Mater. Sci. Eng. A 673, 572 (2016)

[13] K.K. Yogesha, A. Joshi, N. Kumar, R. Jayaganthan, Mater. Manuf. Process. 32, 1336 (2017)

[14] L. Wang, Q.L. Du, C. Li, X.H. Cui, X. Zhao, H.L. Yu, Trans. Nonferrous Met. Soc. China 29, 1621 (2019)

[15] H. Wang, C. Lu, A.K. Tieu, P. Wei, H.L. Yu, Metall. Mater. Trans. A 50, 1611 (2019)

[16] J. Wang, R.G. Hoagland, J.P. Hirth, A. Misra, Acta Mater. 56, $3109(2008)$

[17] X.H. He, H. Shi, Y.D. Zhang, Z.G. Yang, C.E. Wilkinson, A.L. Neal, M. Norfolk, Mater. Sci. Technol. 31, 1910 (2015)

[18] H.A. Hassan, J.J. Lewandowski, Mater. Sci. Technol. 23, 1505 (2007)

[19] W.M. Jiang, F. Guan, G.Y. Li, H.X. Jiang, J.W. Zhu, Z.T. Fan, Mater. Manuf. Process. 34, 1016 (2019)

[20] A. Monireh, R.T. Mohammad, S. Morteza, A.I.K. Leo, J. Mater. Sci. 53, 12553 (2018)

[21] J. Wang, L.L. Zhang, Y. Yu, C.Y. Fu, China Mech. Eng. 30, 994 (2019)

[22] G.P. Liu, P. Wang, Y.Y. Zhao, D.X. Chang, Rare Met. Mater. Eng. 47, $223(2018)$

[23] F.Q. Xiao, D.P. Wang, W.B. Hu, L. Cui, Z.M. Gao, L.J. Zhou, Acta Metall. Sin. (Engl. Lett.) (2019). https://doi.org/10.1007/ s40195-019-00985-1

[24] M.Z. Quadir, K.D. Lau, N. Afrin, M. Ferry, Compos. Interfaces 22(1), 13 (2015)

[25] H.L. Yu, A.K. Tieu, C. Lu, X. Liu, A. Godbole, H.J. Li, C. Kong, Q.H. Qin, Sci. Rep. 4, 5017 (2014)

[26] F. Liang, H.F. Tan, B. Zhang, G.P. Zhang, Scr. Mater. 134, 28 (2017)

[27] Z.J. Wang, M. Ma, Z.X. Qiu, J.X. Zhang, W.C. Liu, Mater. Charact. 139, 269 (2018)

[28] H.L. Yu, L. Wang, L.J. Chai, J.T. Li, C. Lu, A. Godbole, H. Wang, C. Kong, Mater. Charact. 153, 34 (2019)
[29] M.K. Pathak, A. Joshi, K.K.S. Mer, R. Jayaganthan, Acta Metall. Sin. (Engl. Lett.) 32, 845 (2019)

[30] Z.W. Huang, S.B. Jin, H. Zhou, Y.S. Li, Y. Cao, Y.T. Zhu, Int. J. Plast. 112, 52 (2019)

[31] T. Bhattacharjee, I.S. Wani, S. Sheikh, I.T. Clark, T. Okawa, S. Guo, P.P. Bhattacharjee, N. Tsuji, Sci. Rep. 8, 3276 (2018)

[32] Y. Takagawa, Y. Tsujiuchi, C. Watanabe, R. Monzen, N. Tsuji, Mater. Trans. 54, 1 (2013)

[33] H.L. Yu, H. Wang, C. Lu, A.K. Tieu, H.J. Li, A. Godbole, X. Liu, C. Kong, X. Zhao, J. Mater. Res. 31, 797 (2016)

[34] S. Mironov, Y. Sato, H. Kokawa, J. Mater. Sci. Technol. 34, 58 (2018)

[35] Y.M. Baqer, S. Ramesh, F. Yusof, S.M. Manladan, Int. J. Adv. Manuf. Technol. 95, 4353 (2018)

[36] T.L. Wang, H.H. Nie, Y.J. Mi, X.W. Hao, F. Yang, C.Z. Chi, W. Liang, J. Mater. Res. 34, 344 (2019)

[37] L. Xu, Y.Y. Cui, Y.L. Hao, R. Yang, Mater. Sci. Eng. A 435, 638 (2006)

[38] M. Mirjalili, M. Soltanieh, K. Matsuura, M. Ohno, Intermetallics 32, 297 (2013)

[39] N. Thiyaneshwaran, K. Sivaprasad, B. Ravisankar, Sci. Rep. 8, 16797 (2018)

[40] M.I. Karpov, V.P. Korzhov, I.S. Zheltyakova, Met. Sci. Heat Treat. 58, 3 (2016)

[41] H.L. Yu, A.K. Tieu, C. Lu, C. Kong, Philos. Mag. Lett. 94, 732 (2014)

[42] Y.N. Han, X.J. Zhang, L. Li, D.J. Zhou, Heat Treat. Met. 42, 45 (2017)

[43] Y.B. Pei, T. Huang, F.X. Chen, M. Zhan, J.Q. Guo, Z. Song, L.G. Bai, Compos. Interfaces (2019). https://doi.org/10.1080/09276 440.2019.1642020

[44] K.M. Karfoul, G.J. Tatlock, Weld. World 63, 841 (2019)

[45] M. Ma, P. Huo, W.C. Liu, G.J. Wang, D.M. Wang, Mater. Sci. Eng. A 636, 301 (2015)

[46] W.S. Hwang, T.I. Wu, W.C. Sung, J. Eng. Mater. Technol. 134, $014501(2012)$

[47] B. Wu, L. Li, C.D. Xia, X.F. Guo, D.J. Zhou, Mater. Sci. Eng. A 682, 270 (2017)

[48] L.S. Fomenko, A.V. Rusakova, S.V. Lubenets, V.A. Moskalenko, Low Temp. Phys. 36, 645 (2010)

[49] R. Jamaati, M.R. Toroghinejad, Mater. Sci. Eng. A 527, 2320 (2010)

[50] M. Movahedi, H.R. Madaah-Hosseini, A.H. Kokabi, Mater. Sci. Eng. A 487, 417 (2008)

[51] H.L. Yu, C. Lu, A.K. Tieu, H.J. Li, A. Godbole, S.H. Zhang, Adv. Eng. Mater. 18, 754 (2016)

[52] L. Geng, H. Wu, X. Cui, G. Fan, Acta Metall. Sin. 54, 1625 (2018). (in Chinese)

[53] H. Mehrer, Diffusion in Solids, Fundamentals Methods Materials Diffusion-Controlled Processes (Springer, Berlin, 2007), p. 155

[54] Y.J. Mi, H.H. Nie, T.L. Wang, X.R. Li, X.W. Hao, W. Liang, J. Mater. Eng. Perform. 28, 4143 (2019)

[55] Y.B. Sun, J. Chen, F.M. Ma, K. Ameyama, W.L. Xiao, C.L. Ma, Mater. Charact. 102, 165 (2015)

[56] X.B. Zhang, Y.B. Yu, B. Liu, Y.C. Zhao, J.Q. Ren, Y.J. Yan, R. Cao, J.H. Chen, J. Alloys Compd. 783, 55 (2019)

[57] L. Qin, M.Y. Fan, X.Z. Guo, J. Tao, Vacuum 155, 96 (2018)

[58] H.L. Yu, C. Lu, K. Tieu, H.J. Li, A. Godbole, C. Kong, Mater. Sci. Eng. A 660, 195 (2016)

[59] N. Rangaraju, T. Raghuram, B.V. Krishna, K.P. Rao, P. Venugopal, Mater. Sci. Eng. A 398, 246 (2005)

[60] S.V. Zherebtsov, G.S. Dyakonov, A.A. Salem, V. Sokolenko, G.A. Salishchev, S.L. Semiatin, Acta Mater. 61, 1167 (2013) 